\title{
Among the reasons for the importance of sports on holiday
}

\author{
Murat SENTUNA ${ }^{1}$, Velittin BALCI ${ }^{2}$, Cenk TEMEL ${ }^{3}$
}

\author{
1 School of Physical Education and Sport, Adnan Menderes University, Aydin, Turkey, \\ ${ }^{2}$ Faculty of Sport Sciences, Ankara University, Ankara, Turkey, \\ ${ }^{3}$ School of Physical Education and Sport, Inonu University, Malatya, Turkey, \\ Address Correspondence to M.Şentuna, tarumnil@gmail.com
}

\begin{abstract}
The purpose of the study, among the causes of the Turkish people go on holiday is to determine the importance of sports and analyzed according to gender, age, income and education levels the causes of sport participation on holiday. 2.104 people participated in this research (1.274 male60.6\% and 830 female $34.4 \%$ between the ages of 16-60). In this study, as a means of data collection "The Opinion Survey About Reasons For Doing Sports On Holiday" was used. Of the participants in the study, noted that a total of 1.527 people (936 male $61.2 \%$, 591 female $38.8 \%$ ) on holiday do sports and 282 participants, into their severity rating ranking, took sports item. In analyzing the data mean, standard deviation, percent, frequency distributions, participants during the holidays as a reason to play sports in the analysis of their answers to the propositions presented, by gender, independent-samples t test and age, education and income levels of the one-way anova analysis were used. Results showed that there are differences according to participants' gender, age, and income and education level. Suggestions presented to the participants "to attend any sporting event as a spectator" 73 people $(25.9 \%)$ never, "as a participant to participate in any sporting activity" 75 people (26.6\%) rarely and "to participate in extreme sports" of 112 people (39.7) always responded. Between men and women, "to find different sports facilities" and "learn a new sport" is a significant difference between the suggestions ( $\mathrm{p}=0.046$ and $0.004<0.05)$ were found. Between $16-25$ years and $46-55$ years of age $(\mathrm{p}=0.046<0.05)$, between 500-1000 TL and 1001-2000 TL $(\mathrm{p}=0.049<0.05)$ and $2001 \mathrm{TL}$ and above $(\mathrm{p}=0.019<0.05)$ income, between post-graduate education and high school $(\mathrm{p}=0.02<0.05)$ and college graduates $(\mathrm{p}=0.003<0.05)$ significant differences were found. As a result of these findings, among people who want to do sport on holiday sex, age, income and education levels may be concluded that differ.
\end{abstract}

Keywords: Sports on holiday, sport tourism, tourism.

\section{INTRODUCTION}

Sports and tourism is the world's most popular leisure time assessment tool and for many participants, between significant differences, offers a unique opportunity for development (24). People can be sports competitors or participants (audience) (32). Whether active or passive participant, where they live or different places to anyone can happen tourism through sports activities (13). On the basis of the effort to define sports tourism, there is leisure time for entertainment or business trips for professional sports participation $(33,11,28)$.

Some researchers define as follows sports tourism. Kurtzman (18) says "the use of sports as a vehicle for tourismendeavours", Standeven and De Knop (29) "sport tourism includes all forms of active and passive involvement in casually or in an organised way for noncommercial or business/commercial reasons, that necessitate travel away from home and work locally" and Stoessel (30) "people who are interested in sports, emerging with their participation in tourism, the totality of events and relationships". However, all three definitions are inadequate for understanding the sports tourism.

As can be seen from the definition tourism, sports and travel terms are used together. Therefore, sports tourism is brought about in various ways. Sport tourism people involved in sports does not mean to travel to another place. At the same time can be said to creating the potential for tourism in traveling to watch a sporting event. In fact, even when traveling can be arranged to visit the places where the major sporting events.

In developing countries in the field of tourism, sports activities and organizations, known to have a significant level of tourism potential $(4,22,14,3)$. However, for sports tourism, the promotion and 
strengthening of the country's image is said to have many advantages. Therefore the relationship of sport and tourism sector is seen to show an increasing trend.

The countries that want to take their own countries world-renowned sports events (the modern Olympic Games, Football World Cup, the Basketball World Championships, etc.) and these organizations if done perfectly, can create very large and high-quality sports tourism potential $(25,17,2)$. In this way, the world-famous athletes to compete or watch, much easier to come to their country and in fact, large fans and professional audiences for these athletes can come. So, make an effective presentation and create the image, it seems much easier.

A person to be called the sports tourists, only to have made a sport branch or travel request is not enough. In addition, an attractive environment, the audience, employees in the organization, other participants, the basic wants and needs, general requests, travel motivation, the consumer's economic, intellectual, social, political, complementary situation it is also important personal travel features (19).

Many researches on sports tourism, focuses on understanding what the behavior of sports tourists $(9,5,32)$.Researchers are trying to find things that lead to the development of sports tourism, to identify what motivates people to behave like that, explain how it affects people and developing new policies and strategies that are trying to decide what should be the future vision (27).

Acoording to the Kurtzmanand Zauhar (19) while people decide to go on a trip or to participate in a sporting event, are affected by external motivators include external rewards, such as money, gifts, media recognition as well as peer prestige.In addition, as a spectator or participants about attend the events, they decide consciously with the knowledge they have acquired.It is important to note that tourists, through their degree of involvement, step into a "magic environment" defined by rules, approaches, procedures and physical constraints. In fact, this new "space" inherently exudes its own time system, taboos, traditions, mannerisms and heros.In media many travel opportunities published from utilizing the charm of sports.

In particular, resorts have become meccas for the active sport tourist. Resorts have become synonymous with their sport and recreation facilities. "Outstanding golf courses can be a major drawing card for resorts" (7). It is no longer sufficient to be located by beautiful beaches, spectacular mountains or famous attractions. Redmond (23) suggests that high quality sport and fittness facilities are a necessity if a resort is to be a successful tourist destination.

Martin (20) asserts that "in these fit times, you don't just stand around admiring exotic destinations, you hike, float, climb, ski, trek, dive, sail, paddle, dogsled, horseback, mountain bike and sea kayak them". Whether tourists want to play golf or tennis, take an aerobics class, or receive instruction in an activity of their choice, the prevailing message in the tourism industry is that sport tourism is the entrepreneurial development of the nineties and as such is gaining mass appeal (19).

Turkey is a country that especially in areas where there are many resorts in the Mediterranean and Aegean coasts and many tourists prefer to holiday abroad. At the same time domestic tourists from within the country is filling this region and the resort primarily in the summer. Every year, many tourists come in the holiday destinations, sports facilities and offers a variety of facilities is rapidly increasing in number for customers.The purpose of the study, among the causes of the Turkish people go on holiday is to determine the importance of sports and analyzed according to gender, age, income and education levels the causes of sport participation on holiday.

\section{MATERALS \& METHODS}

In this study, as a means of data collection "The Opinion Survey about Reasons for Doing Sports on Holiday" was used. Preparing appropriate questions the purpose of the study and preliminary questionnaire was created. The survey was published on the internet to reach more easily. This preliminary survey was carried out by 20 people, according to the answers given which is created by adjusting the application form. In the first part of the survey consists of four parts, to describe the demographic characteristics of the participants gender, age, education level, income level has sections. In the second part, were asked whether they sport on holiday, in the third part, to indicate their reasons for doing holiday eleven item was presented. Finally, the fourth section of the persons doing sports holiday in the first three options, to find out the reason for this is given the option of fifteen items.Participants replied as to these questions never, rarely, sometimes, often, always. In 
analyzing the data, mean, standard deviation, percent, frequency distributions were used. In addition, the analysis of the responses to items given as a reason to play sports during the holidays, Independent samples t-test to investigate differences according to sexand to determine the differences among age, education and income one-way Anova was used.The data was analysed in SPSS 18.00 package program by descriptive statistic techniques. Cronbach alfa was found to 0.731 .

\section{RESULTS}

In this research 2.104 people participated (1.274 male, 830 female). Participants' gender, age, education and income levels, frequency and percentage distribution are shown in Table 1.

Table 1. Participants' gender, age, education and income levels, frequency and percentage distributions.

\begin{tabular}{|c|c|c|c|}
\hline & Groups & $\mathrm{n}$ & $\%$ \\
\hline \multirow[t]{2}{*}{ Gender } & Male & 1274 & 60.6 \\
\hline & Female & 830 & 34.4 \\
\hline \multirow[t]{5}{*}{ Age } & $16-25$ & 801 & 38.1 \\
\hline & $26-35$ & 757 & 36.0 \\
\hline & $36-45$ & 410 & 19.5 \\
\hline & $46-55$ & 117 & 5.6 \\
\hline & 56 and above & 19 & 0.9 \\
\hline \multirow[t]{3}{*}{ Education } & High School & 88 & 4.2 \\
\hline & Bachelor & 1418 & 67.4 \\
\hline & Master & 598 & 28.4 \\
\hline \multirow[t]{3}{*}{ Income } & $500-1000 \mathrm{TL}$ & 657 & 31.2 \\
\hline & $1001-2000 \mathrm{TL}$ & 879 & 41.8 \\
\hline & 2001 and above & 568 & 27.0 \\
\hline
\end{tabular}

In the second part of the study, 1527 participants (936 male, $61.2 \%$ and 591 female, 38.8\%) were told that doing sport on holiday.

The participants saying that doing sport on holiday, choose the eleven items that may be the reason to go on holiday in the third part of the study. Three items of their choice was requested according to the severity rating ranking.

282 participants, into their severity rating ranking, took sports item. 32 participants $(11.3 \%)$ in the first, 92 participants $(32.6 \%)$ in the second and 158 participants $(56.1 \%)$ choose the third.

In the fourth part of the study, stated that it is important for them to sports while on holiday for 282 participants, fifteen questions were asked. All substances were asked to evaluate as never, rarely, sometimes, often, always.
Table 2. The options to given to the participants; why do you go on holiday?

$\begin{array}{ll}1 & \text { See new places and gain new experiences } \\ 2 & \text { Historical and religious places to see and participate in } \\ 3 & \text { cultural activities } \\ 4 & \text { Get relax } \\ 5 & \text { Adventure / excitement } \\ 6 & \text { Sun, sand, sea and fun } \\ 7 & \text { Shopping } \\ 8 & \text { Sports } \\ 9 & \text { Health } \\ 10 & \text { Romance } \\ 11 & \text { Other (Education, fashion, prestige-status, ....) }\end{array}$

Table 3. The options to given to the participants: If you want to do sports on holiday, the following substances how effective are it for you?

1 To attend a sporting event as a spectator

2 To attend a sporting event as an athletes

3 To make a different holiday

4 In order to gain athletic skills

To keep my fit

6 To live through sports excitement

To establish new friendships and relationships through sport

8 To live new experiences in sport

9 I have bored of other holiday options

10 To take advantage of the sports facilities in hotels

11 To benefit from different sports options

12 In order to participate in outdoor sports

13 Doing sports to relax

14 To learn the kinds of sports that can be done during the

14 holidays

15 To learn any sport

The answers given in the fourth section are; 73 participants $(25.9 \%)$ for the first item (to attend a sporting event as a spectator) responded as never, 75 participants (26.6\%) for the second item (to attend a sporting event as an athletes)responded as rarely and 112 participants (39.7\%) for the twelve item (in order to participate in outdoor sports).

Given these responses, the results of one-way Anova analysis conducted to determine whether significant differences between the gender, a significant difference was found between the eleventh (to benefit from different sports options$\mathrm{p}=0.046<0.05$ ) and fifteenth (to learn any sport$\mathrm{p}=0.004<0.05$ ) items.

Age, income, education level and between fifteen propositions to find out whether there is any difference on the average of the responses made by the one-way Anova analysis of variance was reached the following conclusions. 
Table 4. Analysis values between the ages ranges within the given answers.

\begin{tabular}{lccccc}
\hline Age & N & Mean & Sd & F & P \\
\hline $16-25$ & 107 & 3.359 & 0.609 & 2.498 & $0.043^{*}$ \\
$26-35$ & 91 & 3.354 & 0.584 & & \\
$36-45$ & 56 & 3.220 & 0.579 & & \\
$46-55$ & 24 & 2.991 & 0.507 & & \\
56 and above & 4 & 3.100 & 0.559 & & \\
Total & 282 & 3.295 & 0.593 & & \\
& & & & & \\
$*$ p $<0.05$ & & & & &
\end{tabular}

According to the analysis results, a significant difference was found $(\mathrm{p}=0.043<0.05)$. In Post-Hoc analysis was conducted to find out the difference between the groups, a significant difference was found between $16-25$ and $46-55$ age $(\mathrm{p}=0.046<0.05)$.

Table 5. Analysis values between the incomes ranges within the given answers.

\begin{tabular}{lccccc}
\hline Income & $\mathrm{N}$ & Mean & $\mathrm{Sd}$ & $\mathrm{F}$ & $\mathrm{p}$ \\
\hline $500-1000 \mathrm{TL}$ & 82 & 3.452 & 0.524 & 4.224 & $0.016^{*}$ \\
$1001-2000 \mathrm{TL}$ & 96 & 3.244 & 0.687 & & \\
$2001 \mathrm{TL}$ and above & 104 & 3.217 & 0.528 & & \\
Total & 282 & 3.295 & 0.593 & & \\
& & & & & \\
${ }^{*} \mathrm{p}<0.05$ & & & & &
\end{tabular}

According to the analysis results, a significant difference was found $(\mathrm{p}=0.016<0.05)$. In post-hoc analysis was conducted to find out the difference between the groups, a significant difference was found between 500-1000 TL and 1001-2000 TL income $(\mathrm{p}=0.049<0.05)$ and between 500-1000 TL and 2001 TL and above income $(\mathrm{p}=0.019<0.05)$.

Table 6.Analysis values between the education levels ranges within the given answers.

\begin{tabular}{lccccc}
\hline Education & $\mathrm{N}$ & $\mathrm{M}$ & $\mathrm{Sd}$ & $\mathrm{F}$ & $\mathrm{P}$ \\
\hline & & & & & \\
High School & 18 & 3.570 & 0.513 & 7.727 & $0.001^{*}$ \\
Bachelor & 105 & 3.422 & 0.598 & & \\
Master & 159 & 3.179 & 0.573 & & \\
Total & 282 & 3.295 & 0.593 & &
\end{tabular}

${ }^{*} p<0.05$

According to the analysis results, a significant difference was found $(\mathrm{p}=0.001<0.05)$. In post-hoc analysis was conducted to find out the difference between the groups, a significant difference was found between graduate masterand high school $(\mathrm{p}=0.02<0.05)$ and between masterand bachelor $(\mathrm{p}=0.003<0.05)$.

\section{DISCUSSION}

In this study investigated while the Turkish people on holiday want to do sports and which kind of sports prefer. According to the survey results, participants said that they want to do sports on holiday (1527 person, 72.57\%). However, the first thing that came to mind of the participants, it became apparent that not make your holiday sport (282 person, 13.40\%).Sports tourism is conceptualized as a social, economic and cultural phenomenon that arises from the unique interaction of activity, people and place (32). Therefore people after many days work, they might tend to spend more quiet time during the holidays. And to do this, a lot of options. Only one of them to participate in sports activities. According to the results found in this study, the participants said wanted more to participate in outdoor sports during the holidays rather than watch or participate as athletes in any sports activities.

According to the results of a study conducted by Kaplanidou and Vogt (15), sport event experience related to organizational, environmental, physical, social, and emotional aspects. At the same time, the concept of sports tourism appears quite different experience according to the active or passive participation, the location or type of event and due to the different human nature(32).According to this explanation and the results, Turkish people want to participate in sports activities as a passive participant and said they want to participate in outdoor sports activities during the holidays.

Participants' age, income and education levels were examined, were found significant differences in preferred holiday (between 16-25 and 46-55 years of age, between500-1000 TL,1001-2000 TL and 2001 TL above, between master education andgraduate of high school and bachelor).

In USA the highest rates of participation in all sport activities were reported by individuals aged between 25 and 34 years (for tennis, 18-24 years) with high level of household income (1). But the patterns seem to confirm that age, gender and, income (as one indicator of social class) differences are apparent between those Americans who are physically active and those who are not. Moreover, Rudman (26) found that these differences are accentuated over the life course. He found that while participation in sport decreases with age.

According to Kurtzman ve Zauhar (19) to doholiday has eight main motivating factors. 1) 
adventure, 2) change of climate, 3) family visitations, 4) educational, 5) genealogy, 6) antidote to boredom, 7) chance to meet opposite sex and 8) availability of exotic cuisine. These basic eight motivators do vary from person to person, region to region, and culture to culture. All are dependent upon discretionary monies, income, level of education, physical mobility and the like.

In addition Kurtzman (17) says that a household income or wage income multiplier would be more appropriate for sporting events to determine economic gain.

Mc Gehee and Andereck (21) found that women preferred spending time with family and cultural experiences on holiday, whereas men sought opportunities for sport and adventure. These findings are supported by the literature on family decision-making and holidays. In trips where men are the primary planner, sports and physical activity tend to be emphasized.

Gibson (10), the results found in tourism research, said that men and women tend to travel differently. McGehee et al. (21) indicate that women prefer to be with their families and to make cultural trips during the holidays. Moreover, the men who decide to plan his holiday prefer to participate in sports and adventure activities on holiday.

In conclusion; the main objective in doing this research, the Turkish tourists during the holidays whether they choose to do sports, to investigate the causes of what they're preferences. As a result, research has found that people who want to participate in different activities during the holidays. Even if the first option they said prefer the most sporting events through these activities. Participants also while on holiday plans, in places where sports facilities that they would like to go on holiday.

The results of the study age, gender, income level and education level were found to affect the tendency to sport on holiday. World Tourism Organisation (34) says tourism will increase demand for active holidays. And traditional sun-sea-sand holiday requests will be reduced.

Acoording to the Villers (31), tourism and sport represent the best of humanity and they teach us more about ourselves and we learn how to understand and cooperate with other people. Many areas for cooperation between sport and tourism bodies have been identified. Collaboration between these two sectors needs to be further developed as well.The contribution of sport and tourism should not only be measured in terms of its economic benefits, but also in terms of their social, cultural and educational value, as well as the contribution it makes to national unity and the international image of the country. This means that not all actions can be measured in terms of their strict return on investment figures.

As a result of this research, between women and men the thought of doingholiday, it was determined that there are some differences. In addition, income and education also affect the choice holiday. At the place of holiday, people who want to participate in sports activities are widely made prefer outdoor sports.

In future studies, number of participants should be increased by adding different age category, education level and income level. Participants were selected from only a tourist area.

\section{REFERENCES}

1. Bureau of the Census. Statistical abstracts of the US, 1995: The National Data Book. 115th Edn, Bureau of the Census, Washington DC, 1995.

2. Cassidy F. What motivates event tourists? In: proceedings of business and information. Academy of Taiwan Information Systems Research, International Conference on Business and Information, 12-14 July, Singapore, 2006.

3. Coleman C, Ramchandani G. The hidden benefits of non-elite mass participation sports events: An economic perspective. International Journal of Sports Marketing \& Sponsorship, $2010 ; 24-36$.

4. Devine A, Devine F. The politics of sports tourism in Northern Ireland. Journal of Sport Tourism, 2004; 9(2): 171182.

5. Downward P. Critical (realist) reflection on policy and management research in sport, tourism and sports tourism. European Sport Management Quarterly, 2005; 5(3): 303-320.

6. Gammon S, Robinson T. Sport and tourism: A conceptual framework. Journal of Sport Tourism, 2003; 8(1): 21-26.

7. Gee C. Resort development and management. Educational Institute of the American Hotel and Motel Association, 1988.

8. Gibson HJ. Active sport tourism: Who participates? Leisure Studies, 1998, 17, 155-170.

9. Gibson HJ. Moving beyond the 'what is and who' of sport tourism to understanding 'why'. Journal of Sport Tourism, 2004; 9(3): 247-265.

10. Gibson HJ. Sport tourism (Sport in the global society). Paperback, Routledge, 2006; 76-77.

11. Hall CM. Hallmark tourist events: Impacts, management and planning. London, Belhaven Press, 1992-1.

12. Hall CM. Adventure, sport and health tourism, in special interest tourism (Edited by B. Weilwe and CM. Hall). Bellhaven Press, London, 1992-2, 141-58. 
13. Higham J. Sport tourism destinations-issues, opportunities and analysis. Elsevier Butterworth-Heinemann, Jordan Hill, Oxford, 2005, 6-7.

14. Hinch Thomas D. Canadian sport and culture in the tourism marketplace. Tourism Geographies, 2006; 8(1): 15-30.

15. Kaplanidou $\mathrm{K}$, Vogt $\mathrm{C}$. The meaning and measurement of a sport event experience among active sport tourists. Journal of Sport Management, 2010; 24: 544-566.

16. Kurtzman J. Inaugaural Address, Sports Tourism International Council. Journal of Sport Tourism, 1993; 1(1).

17. Kurtzman J. Economic impact: Sport tourism and the city. Journal of Sport Tourism, 2005-1, 10(1), 47-71, Sports Tourism International Council, Ottawa, Canada.

18. Kurtzman J. Sports tourism categories. Journal of Sport Tourism, 2005-2, 10(1), 15-20 Sports Tourism International Council, Ottawa, Canada.

19. Kurtzman J, Zauhar J. Sports tourism consumer motivation Journal of Sport Tourism, 2005, 10(1), 21-31, Sports Tourism International Council, Ottawa, Canada.

20. Martin K. The fit and adventure some can now holiday by skate. Hartford Courant 13 December, 1992, D4.

21. Mc Gehee NG, Andereck KL. Factors predicting rural residents' support of tourism. Journal of Travel Research, 2004; 43: 131-140.

22. Ralston R, Lumsdon L, Downward P. The third force in events tourism: Volunteers at the XVII Commonwealth Games. Journal of Sustainable Tourism, 2005; 13(5): 504-516.

23. Redmond G. Changing styles of sports tourism: Industry/consumer interactions in Canada, The Usa and Europe, In the tourism industry: An international analysis (edited by MT, Sinclair \& MJ, Stabler) CAB International, Wallingford, UK, 1991, 107-20.
24. Ritchie BW, Adair D. Sport tourism: An introduction and overview. In BW. Ritchie \& D. Adair (Eds.), Sport Tourism: Interrelationships, Impacts and Issues, 2004, 1-29, Tonawanda, NY: Channel View Publications.

25. Ross SD. Developing Sports Tourism. An eGuide for destination marketers and sports events planners, National laboratory for tourism and eCommerce, 2001.

26. Rudman W. Life course socio-economic transitions and sport involvement: a theory of restricted opportunity in sport and aging (edited by B. McPherson). Human Kinetics, 1984; 25-35.

27. Smith B, Weed M. The potential of narrative research in sports tourism. Journal of Sport \& Tourism, 2007; 12(3-4): 249-269.

28. Standeven J. Sport tourism: Joint marketing - A starting point for beneficial synergies. Journal of Holiday Marketing, 1997; 4(1): 39-51.

29. Standeven J, De Knop P. Sport tourism. Champaign, IL: Human Kinetics, 1999.

30. Toskay T. Turizm, turizm olayına genel yaklaşım. Der Yayınları, İstanbul, 1989.

31. Villers DD. Concluding remarks. Journal of Sport Tourism 2003; 8(2): 116-117.

32. Weed M. Sports tourism theory and method: Concepts, issues and epistemologies. European Sport Management Quarterly, 2005; 5(3): 229-242.

33. Weed ME, Bull CJ. Influences on sport tourism relations in Britain: The effects of government policy. Tourism Recreation Research, 1997; 22(2): 5-12.

34. World Tourism Organisation (WTO). Changes in leisure time: The impact of tourism. Madrid, Spain, 1999. 